\title{
Difficult intubation due to outgrowth between the epiglottic fold and the vocal cords: C-MAC ${ }^{\mathrm{TM}}$ to our rescue!
}

Editor, - An elderly, hypertensive, female patient was posted for elective wide local excision with bilateral lymph node dissection and plastic reconstruction of malignant nonhealing ulcer on both angles of her mouth. On airway examination, she was edentulous with adequate mouth opening, normal neck movements and Mallampati grading 2. The onco-surgeons requested a nasotracheal tube to facilitate her reconstructive surgery and for possible postoperative retention of tube. After assessing nasal patency and adequate nasal preparation, a $7 \mathrm{~mm}$ flexomettalic cuffed tube was passed into the left nostril after standard induction of anaesthesia. A Macintosh blade laryngoscope was inserted orally so as to guide the nasal tube into the trachea. The modified Cormack and Lehane grade was 3 (only the tip of the epiglottis was visible). The tube could not be negotiated into the glottis, even with use of a magill forceps or downsizing the tube to $6.5 \mathrm{~mm}$. There was a feeling of the tube hitting a soft structure beneath the epiglottis while advancing it towards the glottis. Hence, the conventional laryngoscope was changed to C-MAC blade for real time visualization. On inserting the $\mathrm{C}$ MAC video-laryngoscope and lifting the epiglottis, there was a mucous overhanging just between the base of the epiglottis and the anterior commissure of vocal cords. This was the structure which was impeding the tube entry

Using C-MAC guidance and a magill forceps, the $6.5 \mathrm{~mm}$ tube was successfully negotiated into the cords by tactfully avoiding the mucous overhanging anteriorly. The rest of the perioperative course was uneventful. Bilateral plastic reconstruction was done after the primary radical surgery and the patient was planned for elective ventilation to allow for graft uptake. The patient was successfully

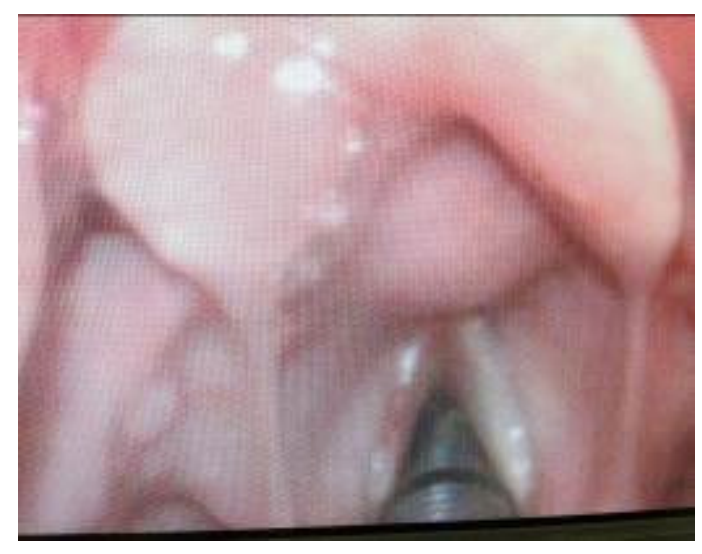

Figure 1 C MAC videolaryngoscopic view showing mucous structure, flexomettalic tube

extubated in the surgical intensive care unit over a tube exchanger device after $24 \mathrm{hrs}$ and later discharged with advice for regular follow-up with the surgical team.

This case highlights the fact that impediment to tube passage can arise at any point during airway management. Adequate preparation for difficult airway (DA) ${ }^{1}$ with ready alternative plans for intubation must be ensured in all such cases, whether anticipated or unanticipated. This was an incidental finding visible on video-laryngoscopic view. It was not a tumorous growth, but a mucous structure and hence no further treatment was planned by the onco-surgeon. Indirect laryngoscopy was not done preoperatively as it was not an ENT surgery or operation on thyroid or larynx. The C-MAC blade ${ }^{2}$ is a useful tool for facilitating difficult intubations under real-time visualization as well as for diagnosing such airway anomalies. Our patient was elderly, edentulous with bilateral ulcers at angle of the mouth. The structure between the anterior aspect of the vocal cords and the base of the epiglottis was a mucous fold, which was hindering the passage of a $7 \mathrm{~mm}$ tube. The intubation became successful once a smaller 
tube was inserted under vision with a C-MAC video-laryngoscope, which is a boon for both unanticipated and anticipated DAs. Caution was also exercised during extubation, which was done the next day over a tube exchanger device ${ }^{3}$.

\section{U Hariharan, SB Shah, BK Naithani,}

Department of Anaesthesia, Rajiv Gandhi

Cancer Institute and Research Centre, Sector

5, Rohini, New Delhi 110085, India.

\section{References}

1. Jeffery LA, Carin AH, Robert AC. Practice guidelines for management of the difficult airway: An Updated Report by the American Society of Anesthesiologists Task Force on Management of the Difficult Airway. Anesthesiology 2013;118(2):1-20.

2. Aziz MF, Dillman D, Fu R, Brambrink AM. Comparative effectiveness of the C-MAC video laryngoscope versus direct laryngoscopy in the setting of the predicted difficult airway. Anesthesiology 2012;116(3):629-36. http://dx.doi.org/10.1097/ALN.0b013e318246 ea34 PMid:22261795

3. Miller K.A, Harkin C.P, Bailey P.L. Postoperative tracheal extubation. Anesth Analg. 1995;80:149-172. PMid:7802273 